\section{Influence of silk clothing therapy in patients with atopic dermatitis}

Min-Hsung Hung, ${ }^{1}$ Dewi Sartika, ${ }^{2}$ Shu-Jen Chang, ${ }^{3}$ Shyi-Jou Chen, ${ }^{4}$ Chih-Chien Wang, ${ }^{4}$ Yi-Jen Hung, ${ }^{5}$ Juin-Hong Cherng, ${ }^{2,6}$ Yaw-Kwan Chiu ${ }^{1}$

${ }^{1}$ Department of Pediatrics, Songshan Branch, Tri-Service General Hospital, National Defense Medical Center, Taipei, Taiwan, R.O.C.; ${ }^{2}$ Department and Graduate Institute of Biology and Anatomy, National Defense Medical Center, Taipei, Taiwan, R.O.C.; ${ }^{3}$ Division of Rheumatology/Immunology/Allergy, Department of Internal Medicine, TriService General Hospital, National Defense Medical Center, Taipei, Taiwan, R.O.C.; ${ }^{4}$ Department of Pediatrics, TriService General Hospital, National Defense Medical Center, Taipei, Taiwan, R.O.C.; ${ }^{5}$ Office of President, Songshan Branch, Tri-Service General Hospital, National Defense Medical Center, Taipei, Taiwan, R.O.C.; ${ }^{6}$ Department of Gerontological Health Care, National Taipei University of Nursing and Health Sciences, Taipei, Taiwan, R.O.C.

\begin{abstract}
The existence of red, inflammatory, and chronic itchy condition in the skin is commonly speculated as the presence of Atopic Dermatitis (AD) in patients. The use of silk clothing as a non-pharmacological approach in the management of $\mathrm{AD}$ has been noticed as an effective alternative therapy; however, the evidence based on its usage is poorly served. Hence, we aim to evaluate the effectiveness of using pure silk clothing in the therapy of AD patients. The clinical trial was performed by recruiting 30 patients with $\mathrm{AD}$ for up to 8 weeks of observation. They were instructed to wear pure silk clothing for the whole day without any additional medication and were investigated using the AD-related questionnaires. The findings revealed a significant decrease of $\mathrm{AD}$ occurrence along with a great improvement of patient's quality of life at each time point. Our investigation demonstrated that this treatment promotes good skin appearance, comfort, and remarkable improvement in the quality of life. This promising preliminary outcome warrants a further study; hence, it can be a potential non-pharmacological treatment choice for controlling the severity of AD.
\end{abstract}

\section{Introduction}

Atopic Dermatitis (AD) is a serious health issue worldwide, particularly in many developing countries, and its incidence is still steeply increasing. $\mathrm{AD}$, which is commonly noticed as a redness and itchiness of the skin, is not only perceived in early childhood but can occur at any age. The symptoms can become severe and tend to present a chronically repeating flare, defined by serious eczema, a typical distribution of skin lesions, and a family history of atopic diathesis. ${ }^{1}$ Indeed, AD can significantly lower the quality of life of the affected patients, such as hampering their social and family interactions, lowering selfesteem, causing uncontrolled emotional distress, and sleep disturbances. ${ }^{2,3}$ This condition leads to the requirement of additional intensive therapy besides the use of medication, that not only cures the symptoms but also focuses on flare prevention and skin stabilization.

The use of topical steroids is still considered as a standard therapy for AD; however, their application becomes a major health concern when regarding the longterm side effects. As a consequence, many patients are keen to explore non-pharmacological therapy for the management of AD. Basically, it is important to focus the treatment on relieving the symptoms and avoiding specific and nonspecific trigger factors as well as preventing acute exacerbations. ${ }^{4,5}$ One general trigger factor of AD is physical irritation, e.g. by harsh textile fibers. The prickly nature of general clothing probably causes itching in patients with AD due to the direct contact with the fibers. Hence, the development of textiles-based therapy might offer a new therapeutic approach in the treatment of AD. The eczema severity in $\mathrm{AD}$ patients is also usually correlated with a high quantity of $S$. aureus colonization as bacterial infection. ${ }^{6,7}$ Therefore, besides providing smoother fibers to prevent the itching tendency, the application of textiles with special characteristics is expected to act as a protector from bacteria, viruses, and other skin contaminants. ${ }^{8}$

Silk clothing can be considered as an attractive option in textiles-based therapy for $\mathrm{AD}$ due to their hygienic properties. ${ }^{9}$ Particularly, the thread fibers of silk are strong and consist of filaments with a rounded shape, resulting in excellent smooth fibers that do not cause scratching, friction, or irritate the skin. ${ }^{10}$ The smooth fibers have minimal abrasive effect on atopic skin and facilitates a faster recovery of irritated skin compared to the rough
Correspondence: Yaw-Kwan Chiu, Department of Pediatrics, Songshan Branch, Tri-Service General Hospital, National Defense Medical Center, Taipei, Taiwan, R.O.C.,

Tel.: +886.227642151 ext. 672183

E-mail: yawkwan@gmail.com

Key words: Atopic dermatitis, Silk clothing, Therapy, Questionnaire.

Contributions: Contribution of Juin-Hong Cherng was equal to Yaw-Kwan Chiu in this work.

Conflict of interest: For the remaining authors, no conflicts were declared.

Funding: This study was funded by the TSGH GCRC clinical trial program: 106-137; TSGH (Songshan) medical research program: 10710, 108-16, 108-17.

Acknowledgments: The authors would like to thank all the participants who enrolled in the trial. Mrs. Shu-Lan Yang assisted in the data collection, analysis, and interpretation of results. The clinical trial was initiated by the Silk Association of R.O.C (Taiwan) and Danee Silk International Co., Ltd., and was managed by the General Clinical Research Center of Tri-Service General Hospital.

Received for publication: 13 May 2019. Accepted for publication: 17 October 2019.

This work is licensed under a Creative Commons Attribution-NonCommercial 4.0 International License (CC BY-NC 4.0).

(Copyright: the Author(s), 2019

Licensee PAGEPress, Italy

Dermatology Reports 2019; 11:8176

doi:10.4081/dr.2019.8176

fibers. ${ }^{11}$ This is due to the fact that they can help to maintain the humidity of body by minimizing the sweating circulation and moisture loss that are thought to worsen xerosis. Hence, the use of silk clothing is known as a potential treatment for AD. However, the evidence based on its usage is limited. Consequently, its application is mostly employed as the second therapy choice. In this clinical trial, we aimed to evaluate the possibilities of using pure silk clothing in the therapy of $\mathrm{AD}$ patients. The effectiveness of this textiles-based therapy was evaluated through the following questionnaires: dermatologist inquiry, Chinese Health Questionnaire (CHQ-12), Dermatology Quality of Life Index (DLQI), and Sleeping Habits Questionnaire-Adult (SHQ). 


\section{Materials and Methods}

The clinical trial was approved by the Institutional Review Board (IRB no. 2-10505-106) and General Clinical Research Center (GCRC no. 106-137) of Tri-Service General Hospital, Taipei, Taiwan. In this clinical trial, 30 patients with AD including both children and adults were diagnosed by reputed dermatologists and their characteristics were listed in Table 1. They were provided with a set of pure silk clothing (underclothes type, $100 \%$ silk; Danee Silk International Co., Ltd., Taiwan) and were instructed to wear it for the whole day during the observation period without any additional medication; the patients were not interrupted of their medication routine (if any). The pre- and post-therapy, in order to estimate the comprehensive effects of pure silk clothing intervention in all patients, were assessed by research nurses following $0,2,4$, and 8 weeks of trial.

During the assessments, we investigated and categorized the severe symptoms of AD such as dandruff, redness, swelling, and itching by performing the dermatologist inquiry according to the clinical doctor's experience. The scale of each category in this inquiry had a range from 0 to 3 , representing 'absence' to 'severe', respectively. In addition, all patients were also given the evaluation of questionnaires including health check-up severity (Chinese Health Questionnaire, CHQ-12) to estimate their health condition in coping up with the disease (such as somatic symptoms, anxiety and worry, social dysfunction, poor family relationship, and depression), dermatology quality of life assessment (Dermatology Life Quality Index, DLQI) to estimate the impact of the skin disease on their quality of life, and Sleeping Habits Questionnaire (SHQ) to analyze their sleeping pattern affected by skin dermatitis. In particular for patients who are children, if they are too young to read the questionnaire, it will be read and evaluated by their parents. All the scores of the questionnaires were statistically analyzed by using the Student ' $t$ ' test for independent and paired data. The significance level was set at $\mathrm{P}<0.001, \mathrm{P}<0.01$, and $\mathrm{P}<0.05$.

\section{Results}

\section{The severity of dermatitis}

We evaluated the severity of dermatitis of the patients according to the dermatologist inquiry of clinical doctor's experience; the scores were $4.13 \pm 0.29,0^{\text {th }}$ week; $3.84 \pm 0.32,2^{\text {nd }}$ week; $3.19 \pm 0.37,4^{\text {th }}$ week; and $2.71 \pm 0.356,8^{\text {th }}$ week (Figure 1).
Significant differences were found at $0^{\text {th }}$ to $8^{\text {th }}$ weeks and $2^{\text {nd }}$ to $8^{\text {th }}$ weeks with $\mathrm{P}<0.001$, at $0^{\text {th }}$ to $4^{\text {th }}$ weeks with $\mathrm{P}<0.01$, and at $2^{\text {nd }}$ to $4^{\text {th }}$ weeks and $4^{\text {th }}$ to $8^{\text {th }}$ week with $\mathrm{P}<0.05$. The higher score represents the severe symptoms of AD including dandruff, redness, swelling, and itching, while the lower score represents the weaker symptoms. Based on this investigation, the appearance of $\mathrm{AD}$ symptoms was observed to significantly decrease after one month of therapy. In line, the photographs of the AD sensitive area on the patients including the back of the knee and elbow also displayed an improvement in the outcome (Figure 2: A-F).

\section{Regular health check-up}

We evaluated the regular health checkup of patients by using the CHQ-12 questionnaire during the trial period of $0,2,4$, and 8 weeks. We conducted the following check-up including the cardiovascular, respiratory, sleep, and emotional aspects. The scores of the questionnaire observed at $0^{\text {th }}$, $2^{\text {nd }}, 4^{\text {th }}$, and $8^{\text {th }}$ weeks were $79.18 \pm 1.54$, $81.25 \pm 1.45,80.99 \pm 1.27$, and $83.32 \pm 1.06$, respectively, with $\mathrm{P}<0.01$ significance observed from $0^{\text {th }}$ to $8^{\text {th }}$ weeks and similar significance $(\mathrm{P}<0.05)$ observed between $0^{\text {th }}$ to $4^{\text {th }}$ weeks and $4^{\text {th }}$ to $8^{\text {th }}$ weeks (Figure 3 ).
The higher score of the CHQ-12 questionnaire represents an excellent health condition of patients in facing their disease. Based on this investigation, the health condition of the patients was observed to significantly improve after one month of therapy.

Table 1. Patient characteristics $(n=30)$

\begin{tabular}{lc} 
Patient characteristics & Value \\
Sex, $\mathrm{n}$ & \\
Male & 14 \\
Female & 16 \\
Weight (kg, mean) & 46.8 \\
Height (cm, mean) & 151.3 \\
Ages, $\mathrm{n}$ & \\
$\quad$ Under $10 \mathrm{y}$ & 10 \\
$\quad 10-20 \mathrm{y}$ & 11 \\
$21-30$ y & 7 \\
$\quad 31-40$ y & 2 \\
Duration of AD symptoms (y, mean) & \\
$\quad$ Under $10 \mathrm{y}$ & 2.8 \\
$10-20 \mathrm{y}$ & 3.6 \\
$21-30$ y & 4.8 \\
$31-40$ y & 5.3 \\
\hline
\end{tabular}

y: year; AD: Atopic Dermatitis

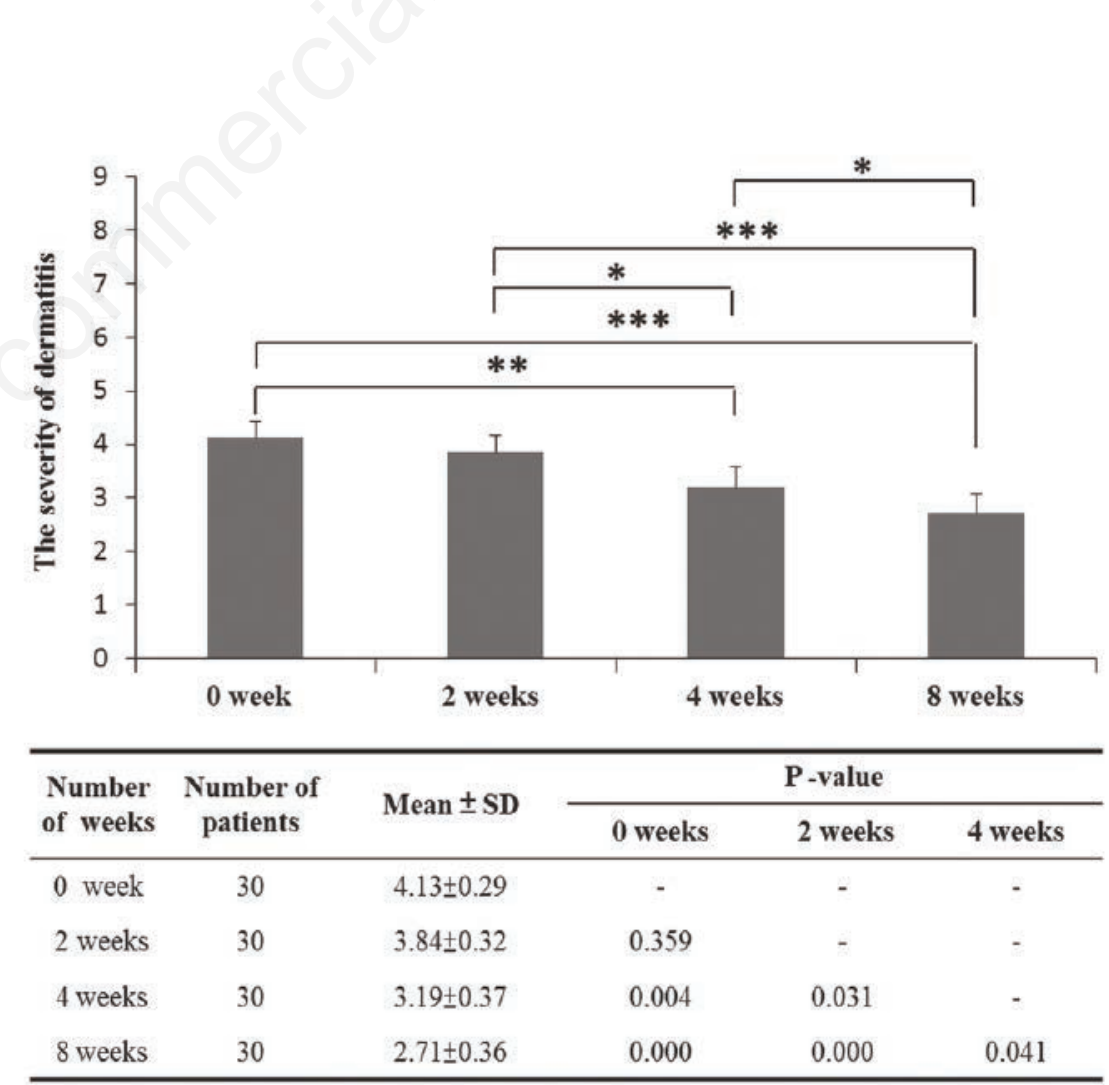

The lower score represents the reduction of symptoms. The statistical values were calculated by $* * * \mathrm{P}<0.001,{ }^{*} \mathrm{P}<0.01$, and $* \mathrm{P}<0.05$.

Figure 1. The severity of dermatitis in patients during the observation period. 


\section{Dermatology life quality index}

We evaluated the dermatology life quality of patients by using the DLQI questionnaire during the trial period of $0,2,4$, and 8 weeks. The DLQI is calculated by summing the score of each question resulting in a maximum of 30 . Notably, the highest score denotes that the quality of life of an affected person is most impaired. The scores of questionnaires observed at $0^{\text {th }}, 2^{\text {nd }}, 4^{\text {th }}$, and $8^{\text {th }}$ weeks were $8.65 \pm 1.09,6.25 \pm 0.86$, $4.70 \pm 0.85$, and $4.35 \pm 0.77$, respectively, with $\mathrm{P}<0.001$ significance observed at $0^{\text {th }}$ to $4^{\text {th }}$ weeks and $0^{\text {th }}$ to $8^{\text {th }}$ weeks and $\mathrm{P}<0.01$ significance observed at $0^{\text {th }}$ to $2^{\text {nd }}$ weeks, $2^{\text {nd }}$ to $4^{\text {th }}$ weeks, and $2^{\text {nd }}$ to $8^{\text {th }}$ weeks (Figure 4 ). In addition, there is no statistical difference at the $4^{\text {th }}$ to $8^{\text {th }}$ weeks. Based on this investigation, the dermatology life quality of patients is observed to pointedly improve after 2 weeks of therapy and afterward.

\section{Assessment of the effect of skin der- matitis on patient's sleeping habit}

Severe dermatitis is known to commonly affect the patient's sleeping habit. The higher score in this questionnaire indicates a better sleeping habit of patients throughout their disease. The scores of the questionnaire observed at $0^{\text {th }}, 2^{\text {nd }}, 4^{\text {th }}$, and $8^{\text {th }}$ weeks were $80.53 \pm 2.04,84.29 \pm 1.89$, $85.71 \pm 1.52$, and $85.29 \pm 2.03$, respectively (Figure 5). Significant differences were found at the $0^{\text {th }}$ to $2^{\text {nd }}$ weeks and $0^{\text {th }}$ to $4^{\text {th }}$ with $\mathrm{P}<0.01$ and at $0^{\text {th }}$ to $8^{\text {th }}$ weeks with $\mathrm{P}<0.05$. Based on this investigation, the sleeping habit quality of patients was observed to remarkably improve after 2 weeks of therapy.

\section{Discussion}

The influence of several factors such as sweating, skin infections, allergens, climatic conditions, and chemical and physical irritants may aggravate Atopic Dermatitis (AD). Besides the use of standard topical medications for $\mathrm{AD}$, alternative treatment applications such as specialized clothing might play an effective role in the protection against stubborn itching and burn inducing factors. Additionally, it might induce skin stabilization and simultaneously heal the $\mathrm{AD}$ symptoms; hence, this method can be used as a long-term therapy with no side effects. The clinical trial reported herein was designed to primarily evaluate the efficacy of pure silk clothing as a potential therapy for AD patients through the questionnaires' investigation.

As expected, the survey results of the dermatitis symptoms in patients with $\mathrm{AD}$
Pre-test
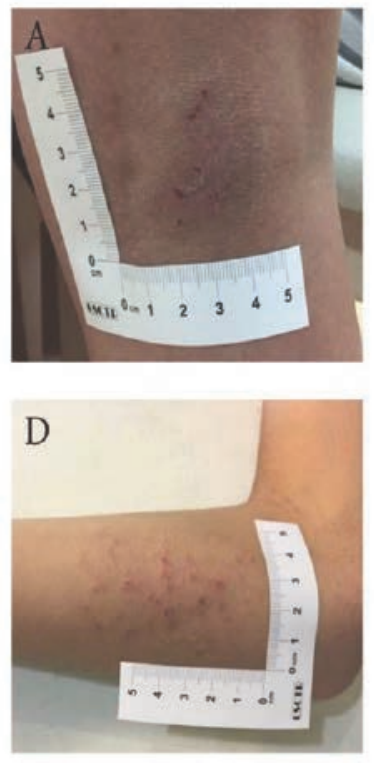

Figure 2. The representations of atopic dermatitis on the back of the knee $(A, B, C)$ and the elbow (D, E, F) treated by pure silk clothing. (A, D, pre-test; B, E, 2-week trial; C, F, 4-week trial).

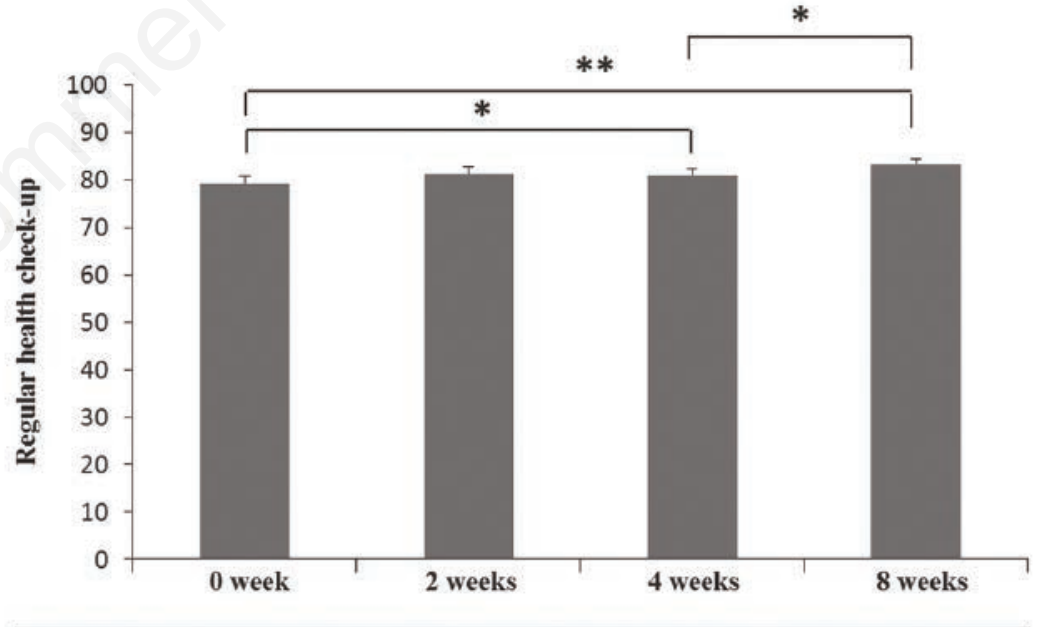

\begin{tabular}{cccccc}
\hline \multirow{2}{*}{$\begin{array}{c}\text { Number of } \\
\text { weeks }\end{array}$} & $\begin{array}{c}\text { Number of } \\
\text { patients }\end{array}$ & Mean \pm SD & \multicolumn{3}{c}{ P-value } \\
\cline { 4 - 6 } & & 0 weeks & 2 weeks & 4 weeks \\
\hline 0 week & 30 & $79.18 \pm 1.54$ & - & - & - \\
2 weeks & 30 & $81.25 \pm 1.45$ & 0.089 & - & - \\
4 weeks & 30 & $80.99 \pm 1.27$ & 0.045 & 0.744 & - \\
8 weeks & 30 & $83.32 \pm 1.06$ & 0.005 & 0.135 & 0.038 \\
\hline
\end{tabular}

The higher score represents an excellent health condition. The statistical values were calculated by *** $\mathrm{P}<0.001,{ }^{* *} \mathrm{P}<0.01$, and ${ }^{*} \mathrm{P}<0.05$.

Figure 3. The regular health check-up of patients (including cardiovascular, respiratory, sleep, and emotional aspects) during the observation period. 
demonstrated that its severity level was significantly decreased after one month of therapy and consistently continued within the therapy period, particularly presented by the lowest score at 8 weeks $(\mathrm{P}<0.001)$ which also denotes a significant reduction of AD indications (Figure 1). Notably, the appearance of dandruff, redness, swelling, and itching was also observed to abate after one month of therapy (Figure 2: A-F). This positive output demonstrated that the pure silk clothing was able to improve the resistance of the skin against AD symptoms, in line with several previous studies. ${ }^{12,13,14}$ The smoothness of silk, especially pure silk, is considerably friendly with the irritated skin by not causing harmful physical contact and enhances collagen synthesis and reduces inflammatory processes during wound healing which is estimated to cure the eczematous lesion rapidly. ${ }^{15}$ In addition, the hygienic property of silk is speculated to act as a skin barrier protector from bacteria, viruses, and other skin contaminants, that help to prevent the aggravation and persistence of the inflammation. ${ }^{16,17}$

Reduction in the quality of life is the other major issue faced by patients affected with $\mathrm{AD}$ and their families during the period of the disease. The patients experience disturbances during sleep caused by nighttime itching and scratching which lead to frustration, along with the psychological pressures such as feelings of guilt, anxiety, resentment, and helplessness. ${ }^{18}$ Upon using the CHQ-12 questionnaire to evaluate the health condition of patients in facing the disease, the results showed that the health quality of $\mathrm{AD}$ patients treated by pure silk clothing exhibited a satisfactory improvement after 4 weeks of therapy and consistently continued within the therapy period, particularly presented by the significant highest score at 8 weeks with $\mathrm{P}<0.01$ (Figure 3). This phenomenon indicated that the therapeutic effect of silk clothing treatment for reducing AD symptoms is a type of physical effect and is not influenced by emotional responses only. In line, the results of the DLQI questionnaire, which evaluated the dermatology life quality, also demonstrated a similar tendency (Figure 4); the significant low impact of skin disease in patients is obtained after 2 weeks of therapy and afterward, with $\mathrm{P}<0.01$ and $\mathrm{P}<0.001$, respectively. Further, the assessment of sleeping habit results revealed a matching finding, in which an improved sleeping habit was confirmed by patients at each week of trial period and consistently continued until the 8 weeks of the therapy period (Figure 5, $\mathrm{P}<0.05$ ). Based on these assessments, it can be concluded that the pure silk clothing not only provided the therapeutic

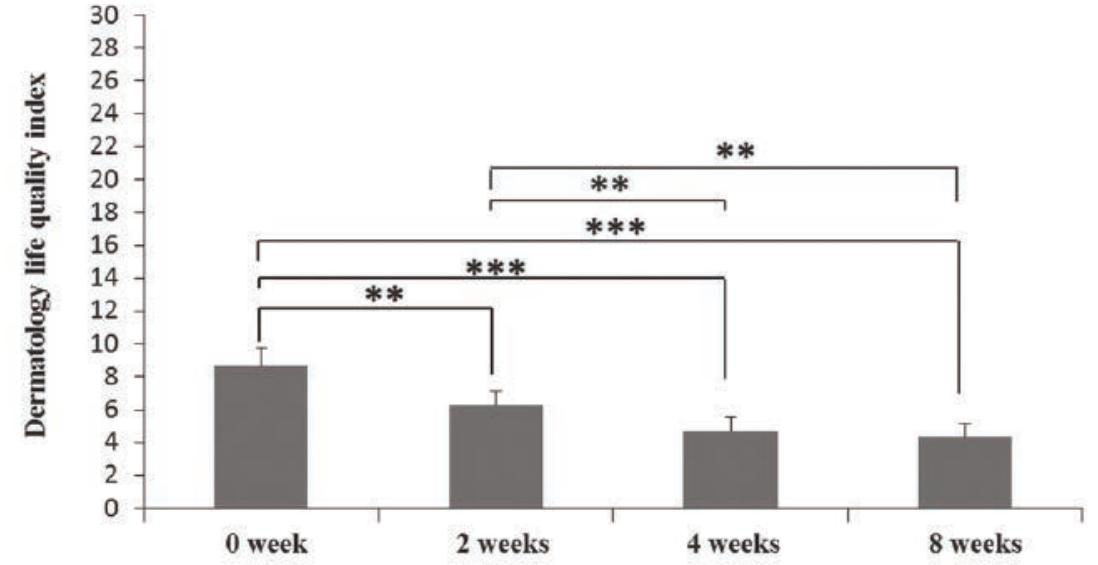

\begin{tabular}{cccccc}
\hline \multirow{2}{*}{$\begin{array}{c}\text { Number of } \\
\text { weeks }\end{array}$} & $\begin{array}{c}\text { Number } \\
\text { of patients }\end{array}$ & Mean \pm SD & \multicolumn{3}{c}{ P-value } \\
\cline { 4 - 5 } & 30 & $8.65 \pm 1.09$ & 0 weeks & 2 weeks & 4 weeks \\
\hline week & 30 & $6.25 \pm 0.86$ & 0.004 & - & - \\
2 weeks & 30 & $4.70 \pm 0.85$ & 0.000 & 0.003 & - \\
4 weeks & 30 & $4.35 \pm 0.77$ & 0.000 & 0.005 & 0.584 \\
\hline
\end{tabular}

A lower score represents the low impact of the skin disease on the quality of life. The statistical values were calculated by ${ }^{* * *} \mathrm{P}<0.001,{ }^{* *} \mathrm{P}<0.01$, and ${ }^{*} \mathrm{P}<0.05$.

Figure 4. The dermatology life quality index of patients during the observation period.

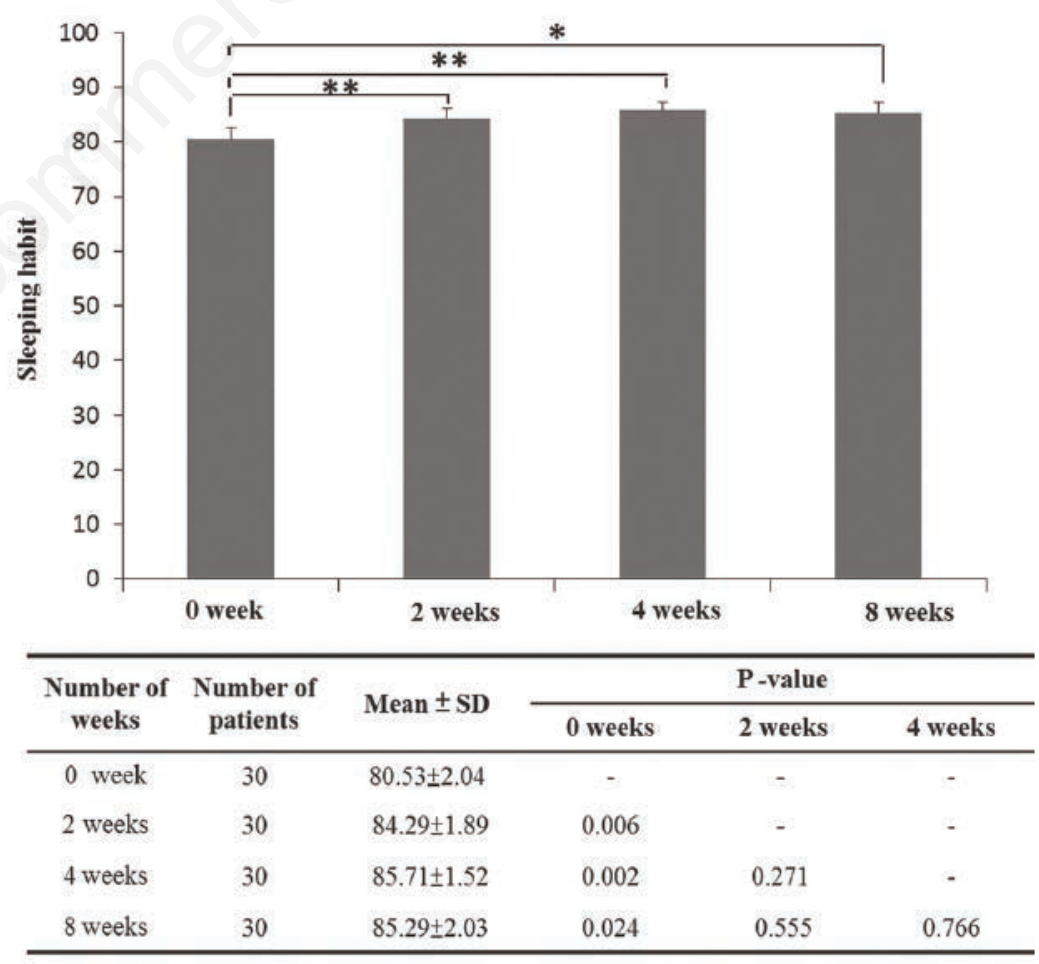

A higher score indicates a better sleep habit of the patients. The statistical values were calculated by $* * * \mathrm{P}<0.001, * * \mathrm{P}<0.01$, and $* \mathrm{P}<0.05$.

Figure 5. The evaluation of the sleeping habit affected by skin dermatitis during the observation period. 
effect to the patients with AD but also comforted their physical and emotional condition which is thought to aid the healing process.

As noted from the results in this clinical trial, the use of pure silk as a clothing-based therapy provides clinical benefit for the patients with $\mathrm{AD}$. It is confirmed generally in 2 weeks of treatment and found to continuously improve the quality of life afterward. Given the beneficial profile and valuable proof-of-concept data of silk clothing for $\mathrm{AD}$ treatment in this preliminary study, the further larger clinical trial is currently ongoing. If confirmed, this outcome can be devoted as a potential non-pharmacological treatment choice for the $\mathrm{AD}$ patients.

\section{Conclusions}

The use of pure silk as a clothing-based therapy generated an appearance of good skin, increased the level of comfort, and improved the quality of life of patients significantly during the management of $\mathrm{AD}$ symptoms. Taken together, our investigation demonstrated that this clothing can be used as an advisable non-pharmacological therapy for controlling the severity of AD.

\section{References}

1. Hanifin JM, Rajka G. Diagnostic features of atopic dermatitis. Acta Derm Venereol Suppl 1980;92:44-7.

2. Leung DY, Boguniewicz M, Howell $\mathrm{MD}$, et al. New insights into atopic dermatitis. J Clin Invest 2004;113:651-57.
3. Rudikoff D, Lebwoh M. Atopic dermatitis. Lancet 1998;351:1715-21.

4. Kessel J, Goldenberg G. Therapies to improve the cosmetic symptoms of atopic dermatitis. Cutis 2016;97:183-6.

5. Akdis CA, Akdis M, Biber T, et al. Diagnosis and treatment of atopic dermatitis in children and adults: european academy of allergology and clinical immunology/PRACTALL consensus report. J Allergy Clin Immunol 2006;118:152-69.

6. He ZP, Fu GW, Geng YF. [Test and evaluation of negative ions textiles]. [Article in Chinese]. Text Dyeing Finish J 2013;35:6-10.

7. Tokura Y. Atopic dermatitis: common extrinsic and enigmatic intrinsic types. In: Kabashima K, ed. Immunology of the skin: basic and clinical sciences in skin immune responses. Tokyo, Springer; 2016. pp 339-58.

8. Jaeger T, Rothmaier M, Zander H, et al. Acid-coated textiles ( $\mathrm{pH}$ 5.5-6.5) --A new therapeutic strategy for atopic eczema? Acta Derm Venereol 2015;95:659-63.

9. Haug S, Roll A, Schmid-Grendelmeier $\mathrm{P}$, et al. Coated textiles in the treatment of atopic dermatitis. Curr Probl Dermatol 2006;33:144-51.

10. Criton S, Gangadharan G. Nonpharmacological management of atopic dermatitis. Indian J Paediatr Dermatol 2017;18:166-73. Available from: http://www.ijpd.in/article. asp? issn=2319-7250; year $=2017$; volume= $18 ;$ issue $=3 ;$ spage $=166 ;$ epage $=173 ;$ aula $\mathrm{st}=$ Criton

11. Hermanns JF, Goffin V, Arrese JE, et al.
Beneficial effects of softened fabrics on atopic skin. Dermatology 2001;202: 167-70.

12. Kurtz EJ, Yelverton CB, Camacho FT, Fleischer AB Jr. Use of a silk like bedding fabric in patients with atopic dermatitis. Pediatr Dermatol 2008;25:43943.

13. Thomas KS, Bradshaw LE, Sach TH, et al. Silk garments plus standard care compared with standard care for treating eczema in children: a randomized, controlled, observer-blind, pragmatic trial (CLOTHES Trial). PLoS Med 2017;14:e1002280. Available from: https://journals.plos.org/plosmedicine/a rticle?id=10.1371/journal.pmed. 100228 0

14. Koller DY, Halmerbauer G, Bock A, Engstler G. Action of a silk fabric treated with AEGIS in children with atopic dermatitis: a 3-month trial. Pediatr Allergy Immunol 2007;18:335-8.

15. Sugihara A, Sugiura K, Morita H. Promotive effects of a silk film on epidermal recovery from full-thickness skin wounds. Proc Soc Exp Biol Med 2000;225:58-64.

16. Agner T. Staphylococcal-mediated worsening of atopic dermatitis: many players involved. $\mathrm{Br} \mathrm{J}$ Dermatol 2010;163:1147.

17. Macias ES, Pereira FA, Rietkerk W, Safai B. Superantigens in dermatology. J Am Acad Dermatol 2011;64:455-72.

18. Drucker, MA. Atopic dermatitis: burden of illness, quality of life, and associated complications. Allergy Asthma Proc 2017;38:3-8. 